\title{
ROLE OF ARSENIC ANTISITE DEFECT IN NONSTOICHIOMETRIC GALLIUM ARSENIDE' ${ }^{\dagger}$
}

J. JASIŃSKI ${ }^{a}, A . K_{\text {URPIEWSKI }}^{a}$, K. KoronA ${ }^{a}$, M. KAMIŃSKA ${ }^{a}$, M.

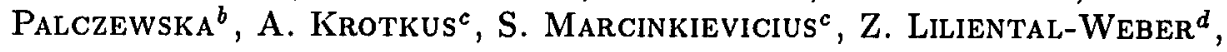
H.H. TAN ${ }^{e}$ AND C. JAGADISH ${ }^{e}$

${ }^{a}$ Institute of Experimental Physics, Warsaw University Hoża 69, 00-681 Warszawa, Poland

${ }^{b}$ Institute of Electronic Materials Technology, Wólczyńska 133, 01-919 Warszawa

'Semiconductor Physics Institute, A. Gostauto 11, 2600 Vilnius, Lithuania

${ }^{d}$ Lawrence-Berkeley Laboratory, 1st Cyclotron Road, Berkeley, CA 94720, USA

${ }^{e}$ Department of Electronic Materials and Engineering

Australian National University Canberra, Australia

Over the last few years there have been many studies of GaAs layers grown at low temperatures $\left(180-300^{\circ} \mathrm{C}\right)$, so called LT GaAs. The interest in LT GaAs was motivated by the potential application of $600^{\circ} \mathrm{C}$ annealed LT GaAs in microwave and fast optoelectronic devices because of its short photocarrier lifetime, reasonable mobility and high resistivity. These properties are associated with the nonstoichiometry of LT GaAs. Recently, studies of comparable material, nonstoichiometric GaAs produced by arsenic ion implantation have been initiated. There is still a strong controversy as to whether the arsenic antisite $\left(\mathrm{As}_{\mathrm{Ga}}\right)$ or arsenic precipitates are responsible for unique electrical properties of both materials. This paper presents the results of structural and electrical studies of high energy As implanted GaAs and comments on relationships between the structure and the resulting electrical properties.

PACS numbers: $73.90 .+$, 78.30. Er

The semi-insulating gallium arsenide (100) wafer implanted with $2 \mathrm{MeV}$ arsenic ions at a dose of $1 \times 10^{15} \mathrm{~cm}^{-2}$ using a $1.7 \mathrm{MV}$ NEC tandem accelerator at the Australian National University were studied. Selected parts of this wafer were annealed for 20 minutes under an arsine ambient at temperatures of 300 , $400,500,600,700$ and $800^{\circ} \mathrm{C}$. The electrical parameters, namely: photocarrier lifetime, conductivity and carrier mobility vs. annealing temperature were studied using time-resolved photoluminescence (PL), and Hall effect. Transmission electron microscopy (TEM), double crystal X-ray diffraction (DCXRD), Rutherford backscattering (RBS), near-infrared (NIR) optical absorption studies and electron paramagnetic resonance (EPR) measurements were applied to understand the influence of implantation and the resulting nonstoichiometry on the structure and the relationships between structure and electrical properties.

tThis work is supported in part by the State Committee for Scientific Research (Republic of Poland) under grants no. 3 P407 02506 and 2 P03B 19408. 
Room temperature time-resolved PL showed very short photocarrier lifetime. The PL signal was monitored at $880 \mathrm{~nm}$ (GaAs band to band transition), giving direct information about the carrier capture time in the material. For the as-implanted and annealed at 300,400 and $500^{\circ} \mathrm{C}$ samples estimated lifetimes were shorter than the resolution of the experimental setup $(0.2 \mathrm{ps})$. For samples annealed at 600,700 and $800^{\circ} \mathrm{C}$ the lifetimes were 1,5 and $10 \mathrm{ps}$, respectively. From room temperature Hall effect study the changes of conductance and mobility vs. annealing temperature were determined. The conductance of an as-implanted sample was almost five orders of magnitude higher than that of unimplanted one. Additionally, the mobility was very low and impossible to measure by Hall effect $\left(<1 \mathrm{~cm}^{2} /(\mathrm{V} \mathrm{s})\right)$. For the annealed samples a gradual decrease in conductance associated with an increase in mobility (which reached a maximal value - about $2000 \mathrm{~cm}^{2} /(\mathrm{V} \mathrm{s})$ - for samples annealed at $\left.600^{\circ} \mathrm{C}\right)$ was observed.

TEM studies gave the direct information on the structure of the material. Figure 1 presents TEM micrographs taken from cross-sectional samples prepared from as-implanted and from material annealed at 300,700 and $800^{\circ} \mathrm{C}$. The implantation caused the formation of a thick $(1.05 \mu \mathrm{m})$ amorphous layer containing small crystalline inclusions. This layer was buried under a thin $(0.08 \mu \mathrm{m})$ fully-crystalline layer with a small concentration of defects. Below the amorphous layer there was a third distinct one of about $0.25 \mu \mathrm{m}$ thickness containing a high density of "end-of-range" defects, as reported earlier for GaAs implanted with
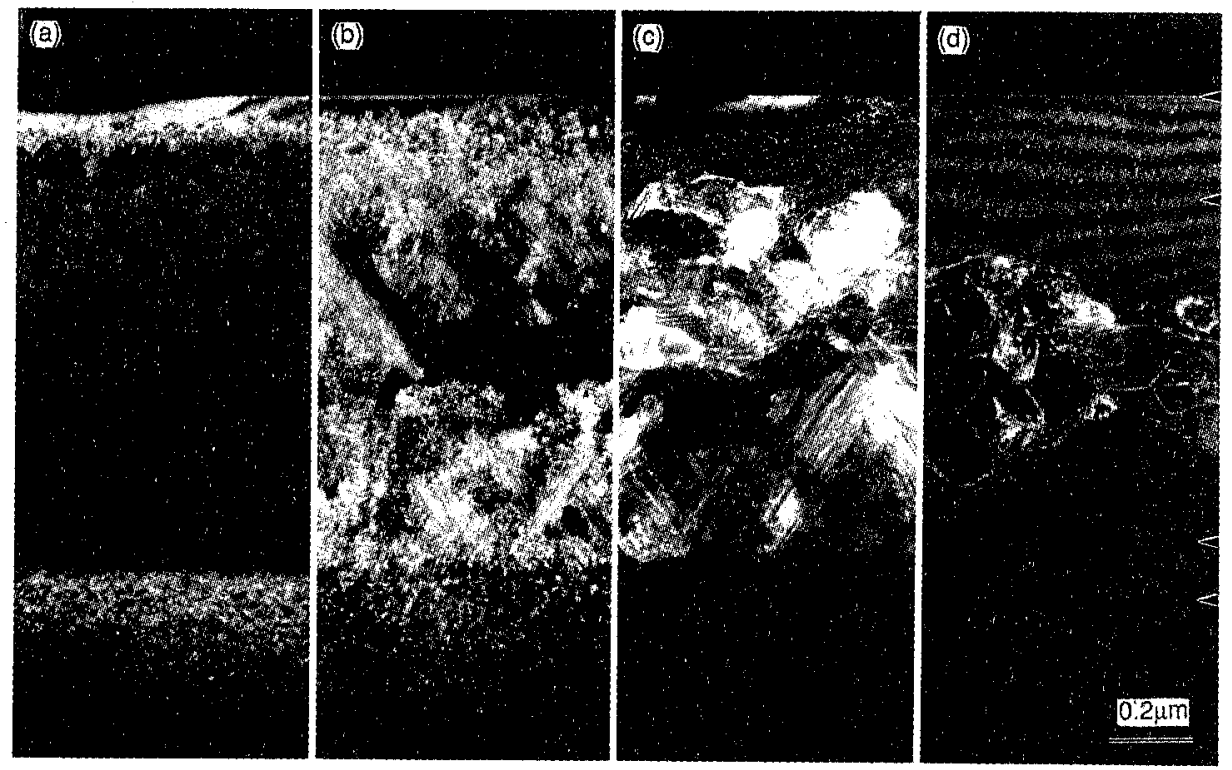

Fig. 1. TEM micrographs of cross-sectional GaAs implanted with $2 \mathrm{MeV}$ As ions samples: as-implanted (a), annealed at $300^{\circ} \mathrm{C}$ (b), $700^{\circ} \mathrm{C}$ (c) and $800^{\circ} \mathrm{C}$ (d). Two layers containing small precipitates are indicated by arrows for sample annealed at $800^{\circ} \mathrm{C}$. 
$200 \mathrm{keV}$ ions $[1,2]$. In the sample annealed at $300^{\circ} \mathrm{C}$ an early stage of recrystallization was observed. First, the top crystalline layer becomes almost twice as wide $(0.14 \mu \mathrm{m})$ and the concentration of "end-of-range" defects decreases. A more significant change, however, was observed within the middle layer. Solid state recrystallization has proceeded from both the upper and lower interfaces of the buried amorphous layer. Most of the amorphous material, but a small amorphous region between the two crystallization fronts, has recrystallized, forming a large number of microtwins. Annealing at $700^{\circ} \mathrm{C}$ leads to still larger broadening of the top monocrystalline layer up to $0.24 \mu \mathrm{m}$. The middle layer was partly polycrystalline with a grain size of about $0.1-0.2 \mu \mathrm{m}$. "End-of-range" defects were no longer observed.

In the sample annealed at $800^{\circ} \mathrm{C}$ the top layer was of thickness of about $0.45 \mu \mathrm{m}$ and the middle layer, $0.40 \mu \mathrm{m}$ thick, was almost completely polycrystalline with almost no microtwins. In this sample two layers of small precipitates (most likely arsenic) were observed. The first is located at the surface down to $0.2 \mu \mathrm{m}$ depth and the second from $1.07 \mu \mathrm{m}$ down to $1.20 \mu \mathrm{m}$ which corresponded to the location of the top and bottom edges of the As implanted layer. The lack of precipitates in the vicinity of the polycrystalline layer suggested that some of the polycrystalline grains were pure arsenic accumulated from the surrounding areas. TEM results were basically in agreement with those obtained from RBS, DCXRD and optical absorption. RBS spectra showed that implantation induced the formation of a buried, highly damaged layer. Higher-temperature annealing led to decrease in the scattering due to damage, and recovery of crystallinity. The only discrepancy between the RBS and TEM results (probably due to calibration) was the thickness of top crystalline layer.

The main results of the DCXRD study are presented in Fig. 2 showing X-ray rocking curves of the (004) reflection for substrate, as-implanted and all annealed samples. Two peaks originating from the substrate and from the implanted region indicated an expansion of the lattice parameter within the implanted layer. The peak introduced by implantation shifted gradually towards the substrate peak with increase in annealing temperature and eventually merged with it for an annealing temperature of $500^{\circ} \mathrm{C}$. A broad background measured in addition to the narrow substrate peak was probably due to the strained polycrystalline region. A NIR optical absorption study of as-implanted samples showed the existence of an exponential tail in the below-band-gap spectrum characteristic of highly defective material. Annealing led to decrease in the tail and its final disappearance after $600^{\circ} \mathrm{C}$ treatment.

EPR was used to monitor the concentration of $A_{\mathrm{G}_{\mathrm{G}}}$ defect in the material. The characteristic spectrum associated with the defect was observed for samples annealed at 300,400 and $500^{\circ} \mathrm{C}$. For as-implanted sample and those annealed at higher temperatures the $\mathrm{As}_{\mathrm{Ga}}^{+}$concentration was below the detection limit $\left(<1 \times 10^{18} \mathrm{~cm}^{-3}\right)$. The TEM results could help to understand low $A s_{\mathrm{Ga}}$ concentrations in these samples: in as-implanted sample there were few antisite defects probably due to amorphization. The low concentration of arsenic antisite defects in samples annealed at $600^{\circ} \mathrm{C}$ or higher temperatures could be explained by the possible accumulation of excess arsenic in the form of precipitates. 


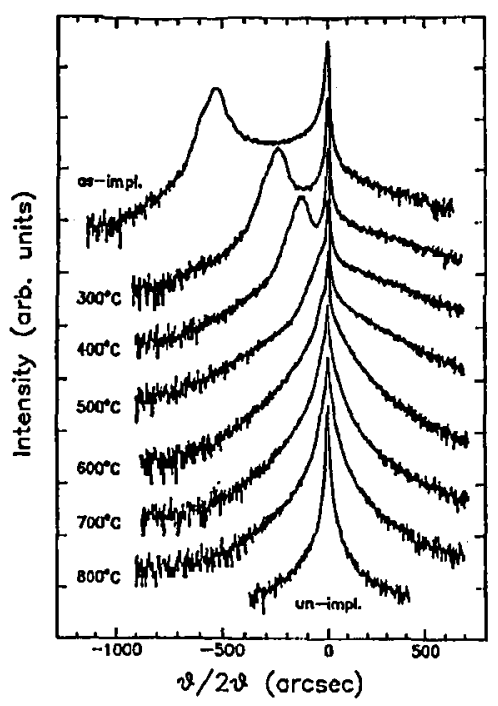

Fig. 2. X-ray rocking curves of (004) reflection of $2 \mathrm{MeV}$ As implanted GaAs as a function of annealing temperature. The unimplanted GaAs curve is shown for comparison.

Information obtained from structural studies shines some light on the free electron behavior in the material [3]. First, implantation leads to partial amorphization associated with an appearance of a high concentration of defects which have electronic states in the GaAs energy gap. These states take part in the hopping conduction, the dominant transport mechanism in as-implanted layers, resulting in high conduction and undetectable carrier mobility. During annealing, when the number of defects decreases the band condution becomes more efficient and starts to dominate. Moreover, the studies suggested that at least two different mechanisms are responsible for the very short photocarrier lifetime. It seems that arsenic antisite defects or defects connected with implantation damage play important roles in the as-implanted and low temperature annealed samples. On the other hand, after annealing at high temperatures, when the concentration of arsenic antisite defects is drastically reduced, precipitates or other structural defects observed by TEM are probably responsible for the photocarrier lifetime shortening.

\section{References}

[1] D.C. Look, Thin Solid Films 231, 61 (1993).

[2] A. Claverie, F. Namavar, Z. Liliental-Weber, Appl. Phys. Lett. 62, 1271 (1993).

[3] Z. Liliental-Weber, F. Namavar, A. Claverie, Ultramicroscopy 52, 570 (1993).

[4] A. Kurpiewski, K. Korona, M. Palczewska, C. Jagadish, J. Williams, M. Kamińska, in: Proc. 8th Conference on Semi-Insulating III-V Materials, Warsaw 1994. 